\title{
Gênero e defesa: uma questão de preferências
}

\author{
Natalia Schwether \\ Andrea Steiner
}

\section{Resumo}

O que explica a ausência de políticas de gênero nos documentos oficiais da defesa brasileira? Para responder, o artigo emprega a técnica de rastreamento de processo, com especial enfoque na busca de evidências empíricas. Sugere-se que tal ausência é resultado, também, da influência militar na política. Isto é, os desafios das mulheres militares brasileiras, como o acesso limitado a certas armas e especialidades, restrições nas formas de ingresso, problemas de infraestrutura e a inexistência de uma legislação que as ampare, são reflexos dos interesses das elites políticas e sua relação com os líderes militares, os quais nem sempre possuem vontade política para introduzir a questão de gênero na agenda, esforçando-se para manter a organização imune mudanças sociais. 
A pesquisa sobre as mulheres nas forças armadas é recente e tem se ampliado progressivamente. Na década de 1970 eram ínfimos os estudos, mas a atenção aumentou à medida que as organizações militares permitiram o acesso às mulheres e lhes atribuíram mais papéis (Segal, 2006). Tais pesquisas possuem diferentes matizes: são produzidas nos departamentos de ciência política, história, antropologia, psicologia, jornalismo e, também, pelo pessoal militar, a partir de suas próprias experiências. Entretanto, sofrem com uma baixa sistematização (Segal, 2006), no que este artigo pretende contribuir ao realizar uma proposição causal e um teste empírico.

Diante das estratégias possíveis, esse artigo escolheu propor e elucidar um processo através de um mecanismo causal capaz de responder à pergunta: o que explica a ausência de políticas de gênero nos documentos oficiais da defesa brasileira? Tendo em conta uma prévia exploração da literatura, aventou-se a possibilidade de uma nova causa, ainda não estudada, ser responsável pelo

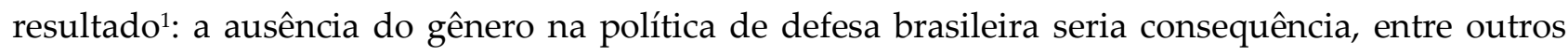
fatores, da influência militar na política.

A principal contribuição deste artigo é rastrear as etapas do percurso entre a causa (influência militar) e o resultado (ausência de políticas de gênero na defesa). Esse rastreamento vai além de uma narrativa descritiva em que eventos são traçados, pois busca explicar o processo causal. Enquanto uma sequência de eventos nos conta quem fez o quê, analisar o mecanismo acrescenta o porquê de algo ter sido feito e, ainda mais importante, a razão dos eventos estarem ligados de determinada maneira (Beach e Pedersen, 2019).

Para tal, este artigo apresenta uma breve contextualização sobre a questão de gênero nas forças armadas, segue detalhando a estratégia empírica utilizada, apresenta o processo causal rastreado e encerra com algumas considerações finais.

\section{Contextualização}

$\mathrm{Na}$ instituição militar, questões de gênero se destacam ao menos em três dimensões: na estrutura da organização, quanto às oportunidades e ocupações; na representação numérica, segregando as mulheres das funções centrais da instituição; e na cultura, pois, mais do que gendrificada, a instituição é gendrificante (Carreiras, 2010). ${ }^{2}$

${ }^{1}$ Algumas das possíveis causas são: i) influência exercida por mulheres quando em posições de chefes de Estado; ii) elaboração de um Plano Nacional de Ação em resposta a Resolução 1325 do Conselho de Segurança da Organização das Nações Unidas; iii) crescente profissionalização das forças armadas e fim da conscrição obrigatória (Schwether, 2020).

2 Entende-se como gendrificante a tentativa de manter a instituição fiel aos seus valores, na qual a ordem androcêntrica prevalece sobre o feminino (Janowitz, 1967; Baaz e Stern, 2009). 
O esforço por manter a organização imune às mudanças fundamenta-se em seu paradigma basilar do guerreiro masculino, que é, ao mesmo tempo, conservador e excludente. Concebido a partir do entendimento de que a atividade básica das forças armadas é o combate, o serviço militar seria, portanto, uma atividade masculina. Tal ideia foi, com o passar do tempo, enraizada em normas e valores, permeando toda a cultura militar (Dunivin, 1997).

O culto ao masculino resulta em um recorrente reforço de estereótipos e binarismos como: o homem ativo vs. a mulher passiva; o homem agente vs. a mulher vítima; o homem racional vs. a mulher emocional. Binarismos estes que mantêm a mulher excluída, especialmente, do ambiente militar (Tickner, 1999; Enloe, 2004).

As forças armadas, tal qual as demais organizações, são, portanto, uma instituição produtora e definidora de gênero. Reificam a masculinidade hegemônica em seus processos e substanciam estereótipos que sugerem superioridade. Por exemplo, o de que os homens são mais disciplinados, mais aptos fisicamente, possuem maior controle emocional e são mais inteligentes e, por isso, são mais capacitados para exercerem as funções demandadas (Segal, 2006; Hinojosa, 2010).

Assim, independentemente do aumento numérico de mulheres na instituição e da maior atribuição de funções nas últimas décadas, ainda há grande resistência quanto à integração efetiva do segmento feminino, em termos de políticas públicas e práticas cotidianas (Segal, 2006). Há discriminação nos processos, condutas, imagens e ideologias, e na distribuição desigual de poder, status e salários (Acker, 1992).

Além de discursos que remetem a uma suposta distribuição natural dos papéis no trabalho (Héritier, 1989), no qual as mulheres são alocadas em posições socialmente sexuadas (ou seja, ocupam, em sua maioria, atividades administrativas e relacionadas à saúde), a distribuição desigual das especialidades configura uma barreira na busca por direitos iguais. Isso é resultado de uma visão reducionista, que distribui os papéis sociais seguindo um determinismo biológico (Caprioli, 2000).

Tal construto destina às mulheres cargos de menor prestígio (Spencer e Podmore, 1987). Observa-se em algumas instituições uma tentativa imperativa de manter as mulheres fora da zona de combate, identificada como distintivamente masculina. Porém, enquanto as mulheres estiverem excluídas desse ambiente, "a masculinidade militarizada ainda estará intacta" (Stern, 2011, p. 568, tradução nossa).

A restrição ao combate estaria associada à debilidade física e psicológica das mulheres, que devem ser constantemente protegidas pelos homens, uma vez que são vistas, quase exclusivamente, como vítimas da guerra. Esse raciocínio agrupa todas as mulheres sob o mesmo estigma e negligencia suas particularidades e diferentes experiências (Alison, 2007; Stern, 2011). 
Do mesmo modo, por terem presença/representação numérica muito inferior à dos homens, as mulheres ganham extrema visibilidade na organização militar e, com isso, sofrem maior pressão para uma ótima performance. Elas são isoladas das redes sociais e encapsuladas de acordo com seu estereótipo de gênero; isto é, são encorajadas a agirem de acordo com uma expectativa predeterminada, especialmente no que tange às ocupações que devem pleitear (Kanter, 1977; Yoder, 1991). ${ }^{3}$

Porém, o aumento do número de mulheres, o que equivaleria a uma integração formal, não resulta, necessariamente, em uma maior integração social (Carreiras, 2004). Afinal, enquanto estiverem em posições de pouca agência, sofrerão com a objetificação (Duncanson e Woodward, 2016) e permanecerão carentes de políticas que minorem as diferenças.

Por se tratar historicamente uma organização de predomínio masculino, são os homens que determinam a condução dos processos na instituição militar. A política organizacional costuma dar pequena relevância à temática de gênero, que é tratada de forma separada e não integra o núcleo das deliberações (Schofield e Goodwin, 2005). O avanço dos interesses femininos é retardado, e as decisões quanto a essa esfera são reativas, ou seja, são tomadas apenas após a ocorrência de um problema (Carreiras, 2004).

Nesse ambiente, o processo de revisão dos valores é mais complexo, "uma batalha monumental, para dizer o mínimo", em virtude do constante reforço de binarismos e da necessária revisão cultural (Dunivin, 1997, p. 23, tradução nossa). Até o momento em que as forças e seus comandantes voluntariamente endossem a diversidade social e o pluralismo, e reduzam as políticas e práticas excludentes, a mudança de paradigma dificilmente ocorrerá (Duncanson e Woodward, 2016).

Para que a perspectiva de gênero deixe de ser um ideal normativo e adentre a política, são necessárias ações como capacitações em gênero, consultas sobre as consequências das políticas nas vidas de mulheres e homens, uso de uma linguagem sensível ao gênero, geração de estatísticas desagregadas e rotinização das práticas promotoras da igualdade de gênero (True, 2010).

Contudo, a efetivação das mudanças está diretamente atrelada aos interesses das elites políticas e sua relação com os líderes militares; é o resultado dessa interação que diz se eles atuarão de forma a aumentar a equidade ou se manterão os privilégios (Stachowitsch, 2012). E nem sempre partidos políticos e forças armadas possuem vontade política para introduzir a questão na agenda.

${ }^{3}$ O estudo de Kanter (1977) foi realizado no âmbito das organizações, e sua teoria ficou conhecida como tokenismo. Pessoas de um subgrupo (menor que 15\% do total) são consideradas tokens. Na organização militar o tokenismo se expressa na figura das mulheres: elas são um pequeno grupo trabalhando em uma ocupação definida tradicionalmente como masculina (Carreiras, 2004). 
De acordo com Winton (2000), a complexidade da mudança militar relaciona-se, por um lado, com as forças externas da estrutura política e social e, por outro, com as características e valores da instituição. A natureza conservadora de ambos os sistemas favorece a manutenção do status quo, de modo que mudanças marginais são mais propensas a ocorrer do que mudanças sociais profundas.

Não obstante a atitude de indiferença para com a temática (Carreiras, 1999; 2004), muitos acadêmicos vêem a instituição militar como um potencial local para transformação da cultura de gênero, haja vista a centralidade que a organização possui na construção do Estado (Silva, 2008) e a importância dela caminhar na mesma direção e conjuntamente com a sociedade a qual defende (Dunivin, 1997).

\section{Estratégia empírica}

A pesquisa ora apresentada adotou como estratégia empírica a técnica do process tracing, que estrutura-se em torno de uma sequência temporal, com o principal objetivo de localizar evidências que elucidem o encadeamento dos eventos mapeados para explicar o fenômeno (Bennet e Elman, 2007). A estratégia faz uso de mecanismos como principal recurso para conectar a causa ao resultado e identificar as razões de sua emergência (Beach e Pedersen, 2013). No primeiro estágio da análise ocorre a elaboração do mecanismo, em seguida, passa-se à operacionalização e identificação das evidências (manifestações observáveis), para, então, proceder-se à coleta de evidências, primárias e secundárias, de cada parte do mecanismo (CDI, 2015).

A aplicação rigorosa da técnica possui especial importância ao se considerar que é frequente, na academia, que trabalhos com uma perspectiva de gênero sejam criticados em razão de uma não cientificidade e/ou incapacidade de produção de um conhecimento racional (Hollan e Ramazanoglu, 2002).

Sejam tais críticas adequadas ou não, em decorrência disso muitos estudos nessa área são marginalizados e tratados como intelectualmente inferiores aos modelos existentes de produção. Como forma de evitar esse isolamento, duas são as opções: validar as hipóteses através de métodos científicos já existentes, ou propor outros critérios para justificar o conhecimento produzido (Hollan e Ramazanoglu, 2002). O artigo segue a primeira linha.

Para tanto, a estratégia de pesquisa associa estudos anteriormente produzidos a uma intensa busca por dados em fontes primárias (leis, decretos, relatórios anuais, notas taquigráficas, atas de reuniões) que aprimorem a compreensão do caso brasileiro. Embora muitos dos dados estejam disponíveis nas páginas eletrônicas das instituições, a Lei de Acesso à Informação foi fundamental para a coleta das informações. 
O intervalo temporal para a busca por evidências inicia em 2014 e encerra-se em 2019. A delimitação desse período parte do estabelecido no documento do Ministério da Defesa (MD) responsável por nortear a confecção dos documentos basilares para área - Sistema de Planejamento Estratégico da Defesa (SISPED). O período considera também a previsão de atualização quadrienal dos documentos. Assim, a Política Nacional de Defesa (PND), aprovada em 2018, começou a ser formulada em 2014, enquanto a PND prevista para 2020 começou a ser prospectada em 2017.

O protocolo de trabalho se assemelha ao de um detetive: buscam-se todos os tipos de rastros, em diferentes fontes, com primazia das primárias. Uma vez localizadas as pistas, elas são sistematizadas de forma a ilustrar o caminho argumentativo proposto.

Não obstante a execução do process tracing gere uma variedade de observações extremamente úteis para elevar a confiança na proposição inicial, frisa-se que o resultado atingido deve ser entendido como uma atualização do conhecimento e não pode ser generalizado para outros contextos.

\section{Rastreamento do processo}

A proposição causal a ser verificada alega que a ausência da questão de gênero na política de defesa brasileira é resultado, principalmente, da influência militar na política (Figura 1).

Figura 1. Proposição causal quanto à ausência de gênero na PD brasileira

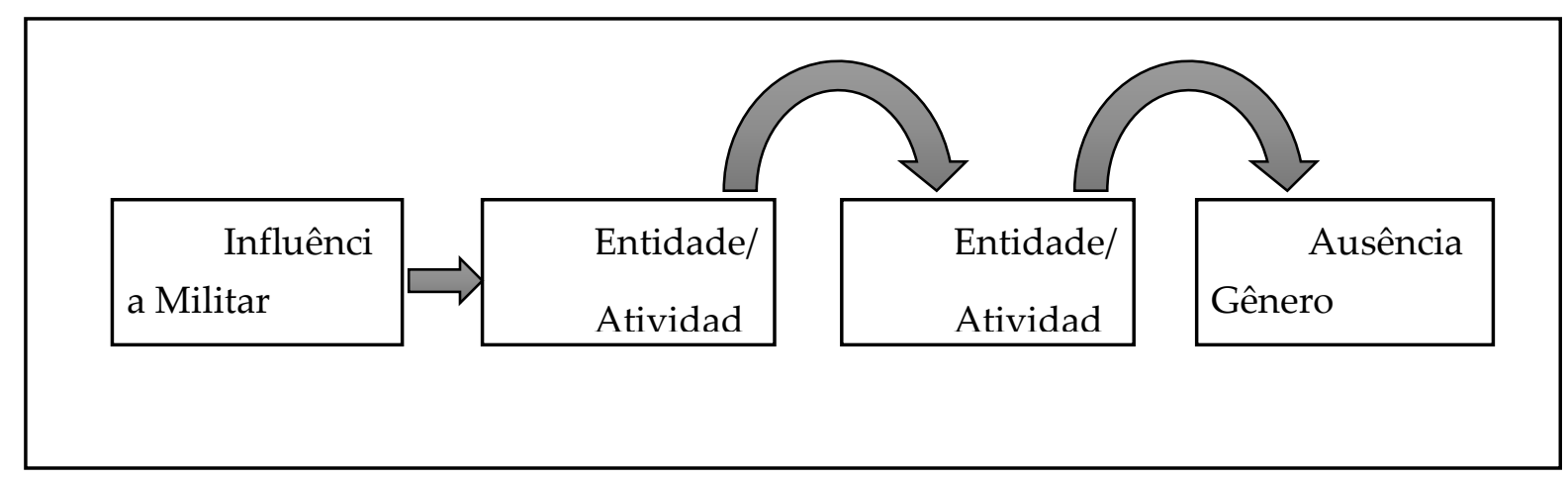

Fonte: Elaborado pela autora (2019). 
O primeiro passo para a construção desse processo é a delimitação do que se entende ser a causa (C) e o resultado (R). Em sequência, são investigadas as manifestações empíricas e evidências observáveis do mecanismo causal.

\section{Delimitação da causa: influência militar}

A influência militar na política - a causa desta análise - é entendida aqui como o envolvimento, mesmo que periférico, de militares no processo político; ou seja, a atuação da instituição militar enquanto grupo organizado e de interesse no sistema político. Esse último é composto por uma série de interações, desde o processo de escolha de objetivos e meios políticos, até a elaboração das normas e dispositivos legais (Melo, 1984).

De acordo com Finer (1962), a instituição militar possui boas razões tanto para intervir na política quanto para se abster. Algumas situações capazes de inibir a intervenção militar são: (1) o profissionalismo militar (quando estão imersos em suas tarefas técnicas, se envolvem menos em questões políticas); (2) a crença na supremacia civil (quando acreditam que as políticas devam ser definidas pelos representantes do Estado eleitos); e (3) o receio de enfraquecer a coesão institucional e a força de combate, uma vez que temas politizados podem gerar divergência de opiniões.

No entanto, são em maior quantidade os fatores que determinam a intervenção: (1) a crença em um destino manifesto (a disciplina e a organização das forças os fariam acreditar ser a única instituição capaz de auxiliar a nação); (2) o exercício de um poder moderador (por possuírem uma identificação especial com o interesse nacional, seriam responsáveis por arbitrar, porém atuam, mais frequentemente impelidas por um desejo de proteger ou estender os seus privilégios); (3) os interesses da classe; (4) os interesses regionais, nos casos em que os corpos de oficiais são formados em uma região específica do país; (5) os interesses corporativos (os militares seriam os únicos capacitados a determinar questões como recrutamento, treinamento e equipamento); e (6) o interesse pessoal (o Exército é tido como um caminho para ascensão de vida, e uma vez no alto escalão das forças manifesta-se o desejo de atingir espaços, também, nos círculos de poder político) (Finer, 1962).

Diante disso, as intervenções podem ser praticadas tanto por atos quanto por omissões. Nos casos em que "as forças armadas restringem a substituição de suas políticas ou pessoas" (Finer, 1962, p. 23), se posicionam contrariamente às pretensões de um governante, ou mesmo se recusam a operar quando convocadas (Finer, 1962).

De acordo com Choi e James (2004) é possível mensurar a influência militar na política de distintas maneiras, tais como: (1) gasto militar (quanto maior o poder de influência dos militares sobre os civis, maiores serão os incrementos nos gastos militares); (2) porcentagem de militares na sociedade (quanto maior o número de militares, maior a probabilidade que suas preferências sejam implementadas na forma de políticas); (3) conscrição obrigatória (um sistema de recrutamento não 
voluntário aumenta a influência militar, uma vez que o regime obrigatório impulsiona um maior gasto militar); por fim, (4) a influência atual pode ser atribuída às influências militares do passado.

Depreende-se, assim, a dimensão histórico-sociológica do fenômeno, qual seja: a existência de forças armadas profissionais, alheias ao mundo político, é um predicado de países que foram capazes, ao longo da construção do Estado, de restringir o papel político dos militares às guerras externas. Em outros contextos, no entanto, tal feito não foi alcançado e, com isso, o envolvimento político das forças armadas se deu sob variadas modalidades. ${ }^{4}$ No caso brasileiro, ele se expressa como um poder tutelar dos governos, em virtude, também, de uma postura oportunista dos políticos que se recusam a se envolver no debate sobre a defesa nacional (Carvalho, 2019).

Embora os militares detenham conhecimentos específicos - derivados, particularmente, do acesso a informações confidenciais e de estudos desenvolvidos ao longo de suas carreiras (Golby e Feaver, 2018) - que podem auxiliar os líderes civis na tomada de decisão (Feaver, 2011), a influência militar é um risco à política. Visto que não são eleitos, o envolvimento de militares na política indica uma diminuição da accountability democrática (PRS Group, s.d, p. 5) e uma fonte de tensão; os membros das forças armadas devem aceitar que a instituição existe para servir ao Estado e não aos seus próprios interesses (Young, 2006).

Na concepção de Stepan (1988), as violações às competências dos representantes eleitos ocorrem em decorrência das prerrogativas militares: "espaços sobre os quais, existindo ou não contestação, os militares, como instituição, pressupõem que adquiriram o direito ou o privilégio, formal ou informal, de exercer um controle efetivo" (Stepan, 1988, p.524-25).

As prerrogativas militares garantem poder ao permitirem que questões latentes da agenda política sejam deslocadas do centro das discussões e impeçam a implementação de outras iniciativas políticas importantes. O tamanho, a centralização e a hierarquização do corpo militar tornam-se grandes entraves para a viabilização política. Em análise comparada empreendida pelo autor, o Brasil destacou-se como o país com maior número de prerrogativas militares: há no país uma situação de "acomodação civil desigual", classificação que o distingue de todas as outras democracias no mundo (Stepan, 1988).

A fragilidade da democracia brasileira estaria nítida em sua Constituição. Nas diferentes redações da Carta Constitucional outorgou-se aos militares um papel fundamental na manutenção da ordem interna, e mesmo após o período ditatorial, buscou-se manter todas as prerrogativas conquistadas (Stepan, 1988). Na Constituição de 1988 estão previstas, por exemplo, a sujeição das polícias militares à instrução militar, ao regulamento militar e à justiça militar. Similarmente, figura

4 As forças armadas podem ser: um braço armado de partidos únicos (países comunistas); controladoras dos governos (Turquia); guardas pretorianos de déspotas (alguns países da América Latina e em países africanos); e, cidadãos armados (Israel) (Carvalho, 2019). 
a responsabilidade da justiça militar de julgar todos os crimes cometidos por militares, exceto os dolosos contra a vida de civis. A segurança presidencial também é realizada por membros, em sua maioria, das forças armadas (Zaverucha, 2005).

Nem a Constituição Federal, nem os posteriores documentos de defesa definiram o papel dos militares no Brasil. Consequentemente, propostas para redução de suas prerrogativas são pouco factíveis (Stepan, 1988).

De acordo com Huntes (1995), a competição política é um estímulo para a redução da interferência militar. Para a autora, os políticos contestariam os militares apenas quando suas ações entrassem em conflito com a oportunidade de obter maior retorno eleitoral. Em situações nas quais as prerrogativas não obstruíssem o apelo eleitoral, elas seriam mantidas. Foi dessa forma que as Forças Armadas brasileiras mantiveram considerável autonomia, principalmente sobre questões corporativas. Os políticos civis, racionalmente, constataram que não teriam ganhos eleitorais tentando reduzir o comando militar sobre tais questões, uma vez que seus eleitores possuíam outras questões mais urgentes.

Adiciona-se a isso o temor de uma reação militar, o que fez com que os presidentes eleitos no Brasil não se propusessem a findar com as prerrogativas, mantendo o padrão estabelecido de altas prerrogativas, conservação dos interesses castrenses e participação militar direta nas decisões que os afetam (Zaverucha, 1998).

\section{Delimitação do resultado: ausência de uma política de gênero para a defesa}

Este trabalho compreende a política de gênero na defesa como um conjunto de políticas que promovem a integração qualitativa das mulheres no ambiente militar, de forma a assegurar direitos e findar com todas as formas de desigualdade e discriminação no ambiente de trabalho.

São exemplos de políticas de gênero medidas práticas como melhorias na infraestrutura da instituição militar, aprimoramentos na legislação, licença maternidade, regulamentação de casamentos entre militares, constituição de espaços para diálogo e redes de apoio e atenção às mães militares.

Igualmente, são imprescindíveis estudos que fundamentem as decisões, instituições para acompanhamento das medidas e promoção de programas de ação afirmativa. Contudo, nem sempre os proponentes das políticas estão atentos às pautas que demandam maior comprometimento e tempo. Priorizam, ao contrário, ações de curto prazo, emergenciais, como a regulamentação das especialidades, classes, armas, serviços e critérios de seleção, adequação das instalações e do uniforme e normas internas (Carreiras, 1999). 
No Brasil, os desafios das mulheres militares alocam-se em duas principais arenas: os de ordem subjetiva e os de ordem prática. Nessa última estão, por exemplo, o acesso limitado a certas armas e especialidades (o que estaria associado, conforme visto anteriormente, à percepção de fragilidade do corpo feminino e à manutenção desse espaço de domínio masculino), as restrições quanto às formas de ingresso, os problemas de infraestrutura e a ausência de legislação (Giannini, Folly e Lima, 2017).

Não obstante a recente atenção conferida às estruturas físicas, falhas (especialmente normativas), carências e atrasos institucionais são facilmente identificáveis, a exemplo de: barreiras que impedem o acesso de mulheres a todas as funções e postos; a precária infraestrutura para maternidade e amamentação no quartel; a inexistência de apoio institucional a militares que vivem em matrimônio ou união com outros militares, especialmente na designação de missões especiais ou de transferência de sede; a não realização de palestras e atividades educacionais sobre a temática de gênero nas organizações militares; a falta de um programa de combate ao comportamento inadequado (assédio, violência sexual e qualquer outro tipo de discriminação de gênero), e o uso de uniformes e equipamentos pessoais que não respeitam as naturais características de gênero (CGMD, 2016b).

Como ilustração, na Academia Militar das Agulhas Negras (AMAN), uma determinação impôs que os desfiles em grupamentos sejam separados por sexo. Na Força Aérea e na Marinha, as alterações curriculares, quando da entrada feminina, se demonstraram inadequadas e prejudiciais às mulheres. ${ }^{5}$ Acresce-se a isso a restrição, até 2016, do ingresso de meninas nas escolas militares em regime de internato, o que ocasionou maiores dificuldades nos concursos e na adaptação às Academias. Apenas em 2017 a Escola Preparatória de Cadetes do Ar (EPCAr) permitiu o acesso feminino. Na Escola Preparatória de Cadetes do Exército (EsPCEx), em 2019, foram ofertadas 400 vagas para homens e 50 para mulheres. O Colégio Naval, contudo, permanece restrito aos candidatos do sexo masculino.

É digno de nota, também, a não atualização dos currículos das instituições militares. Diante disso, o conjunto de disciplinas ofertadas nos cursos de formação e de pós-formação de oficiais da Escola Naval, AMAN e AFA permanece sem alterações (Lima, s.d). Por conseguinte, discussões a respeito da participação feminina não são promovidas.

${ }^{5}$ No caso da AFA, o salto de paraquedas foi excluído do currículo da Intendência em 1996, quando as mulheres ingressaram. A exclusão gerou desconforto entre os cadetes e aumentou as piadas com a primeira turma. A partir de 2003, quando foram abertas as vagas para mulheres na aviação, o salto voltou a compor o currículo de todas as armas. Na Escola Naval, a primeira turma com intendentes mulheres, em 2014, sofreu a supressão da disciplina de física. Com o tempo, notou-se, no entanto, que estavam capacitando intendentes de forma distinta e a primeira turma realizou um supletivo (Giannini, Folly e Lima, 2017). 
Igualmente, a inadvertência na distribuição de uniformes masculinos às recém egressas gerou prejuízos ao desempenho das funções, bem como promoveu a masculinização. ${ }^{6}$ De mais a mais, a rigidez com que os relacionamentos são tratados, a obrigação de comunicar o início de um namoro, a proibição de casamentos (permitido apenas na AMAN) e de gravidez na Escola Naval e a obrigatoriedade de mulheres grávidas de trancarem seus cursos na AMAN e na AFA e, no caso de um aborto, serem automaticamente desligadas, obstruíram uma integração efetiva das mulheres (Giannini, Folly e Lima, 2017).

Também ressalta-se que a precária infraestrutura das instituições para recém-nascidos e crianças pequenas, em virtude da inexistência de creches, ocasiona dificuldades especiais para as mães. Finalmente, o Código Penal Militar defasado não contempla o assédio sexual entre os crimes. Atrelada a isso, a estrutura hierárquica recorrentemente reforçada nos regulamentos disciplinares constrange as vítimas de assédio e as denúncias.

\section{Etapas do mecanismo causal: definição, ausência e abstenção}

O mecanismo, com suas etapas, é responsável pela essência da explicação, e liga a causa (influência militar) ao resultado (ausência de gênero na política de defesa). Para tanto, é descrito em termos de entidades (atores, organizações e estruturas) desempenhando atividades. Tomaremos como base o SISPED, sistema que estrutura o processo de planejamento estratégico no MD em quatros fases: 1) Análise, 2) Formulação da Política e Estratégia Nacionais, 3) Formulação da Política e Estratégia Setoriais e 4) Formulação de Planos (Brasil, 2015).

O processo se desenvolve por meio do estabelecimento de grupos de trabalho compostos por representantes do $\mathrm{MD}$, das Forças Armadas e de outros órgãos governamentais e não governamentais. Os documentos com fins estratégicos têm previsão de atualização quadrienal, coincidindo com o planejamento orçamentário do MD que, por sua vez, está submetido ao cronograma orçamentário federal - Planos Plurianuais (PPA) (Brasil, 2015).

Nos limitaremos, contudo, à análise da primeira e da segunda etapa, uma vez que trataremos aqui da ausência de gênero no documento-maior do planejamento estratégico, responsável por orientar a formulação de todos os demais documentos da área.

Assim, o processo que liga os dois extremos da cadeia causal na nossa análise pode ser descrito na seguinte formulação: em uma tentativa de manter os valores e a ordem androcêntrica prevalecente na instituição (Baaz e Stern, 2009), os militares utilizam de suas prerrogativas para influenciar a política, desde o processo de formação da agenda, perpassando a sua elaboração, até a

${ }^{6}$ As mulheres deveriam se vestir e se comportar em conformidade com a imagem socialmente construída do profissional militar masculino. 
implementação (ou ausência dela). Ao longo desse processo os debates ficam limitados a questões seguras (Bachrach e Baratz, 1962), enquanto as questões de gênero são descredenciadas, retardadas ou mesmo ignoradas. Diante de uma audiência não envolvida e da falta de conhecimento dos líderes civis, aprova-se uma política de defesa que não se atém ao gênero. Essa construção é ilustrada na Figura 2.

Figura 2. Cadeia causal ligando a influência militar à ausência de gênero na política de defesa brasileira

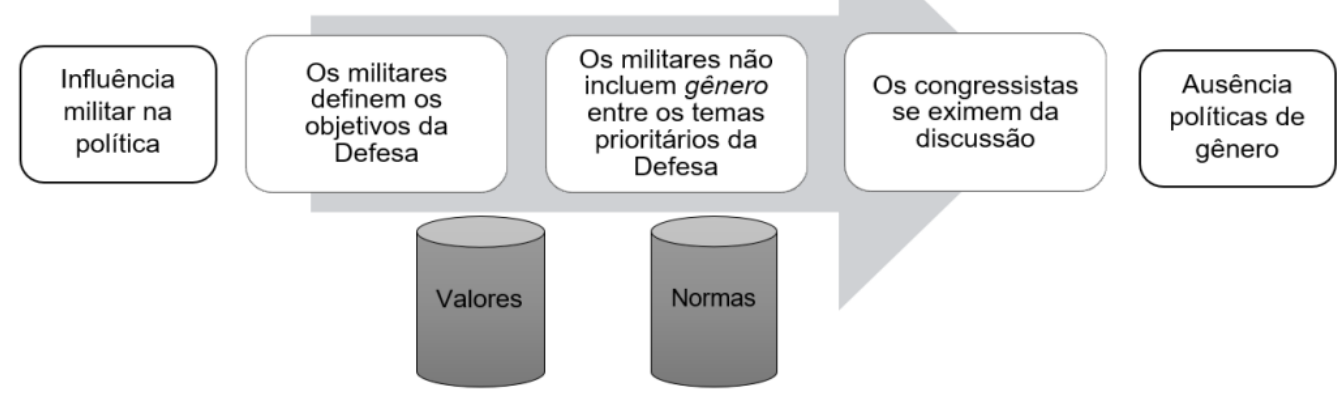

Fonte: Elaborado pela autora, 2019.

Diante disso, apresentaremos, em cada um dos subtópicos, as evidências encontradas para os elos dessa cadeia causal.

\section{Definição dos objetivos da defesa}

A primeira etapa do mecanismo causal sugere que os próprios militares definem os objetivos da defesa. Para testar essa proposição, o trabalho de detetive começa averiguando como se dá a primeira fase do planejamento estratégico da política de defesa, isto é, a fase de análise.

Nesse momento, é feito um diagnóstico dos ambientes interno e externo, e são prospectadas as oportunidades e ameaças, sob a coordenação da Assessoria Especial de Planejamento do Ministério da Defesa, com a participação dos comandantes das três Forças, do Estado-Maior Conjunto das Forças Armadas (EMCFA) e das respectivas chefias e subsecretarias; de forma eventual, instituições públicas e privadas são convidadas (Ministério da Defesa, 2015).

Uma das atividades realizadas é o Projeto Cenários de Defesa, coordenado pelo Centro de Geopolítica e Estudos Estratégicos da Escola Superior de Guerra (ESG), em conjunto com o EMCFA 
e as Forças Singulares (ADESG, 2019).7 O Projeto visa identificar fatos e situações conjunturais ou estruturais relacionados à defesa do Brasil, e elaborar cenários com o objetivo de obter insumos para o desenvolvimento da PND e da Estratégia Nacional de Defesa (END). Com esse propósito, foram organizadas, ao longo do ano de 2019, reuniões em diferentes regiões para coletar dados e informações relevantes para a área (CMNE, 2019). A única reunião com significativa participação de outras instituições da sociedade, além das instituições militares locais, foi a realizada na região sul do país (NEE-CMS, 2019).

Uma segunda atividade associada à primeira fase do planejamento estratégico é a Jornada de Estudos Estratégicos. Sua realização é atribuída ao EMCFA desde sua primeira edição, em 2014. O propósito da Jornada é semelhante ao Projeto Cenários de Defesa, e caracteriza-se por encontros que visam colher subsídios para atualização dos documentos de defesa (Ascom, 2015).

A IV Jornada de Estudos Estratégicos, realizada no mês de outubro de 2017, contou com onze exposições, dentre as quais apenas três foram realizadas por instituições e/ou pessoas não diretamente associadas às Forças Armadas e ao MD. Porém, mesmo nessas oportunidades a moderação do painel foi de responsabilidade de militares. Nota-se, portanto, que embora a proposta da Jornada fosse o aprofundamento das relações entre os órgãos responsáveis pela defesa, academia e sociedade, houve o encerramento das questões no âmbito militar.

Dessa forma, embora esteja prevista no SISPED a convocação de instituições públicas e privadas para integrar a primeira fase de definição dos objetivos da defesa, as evidências encontradas mostram que há uma participação majoritária de entidades e representantes da instituição militar na produção de estudos que norteiam os documentos.

Em suma, o alto nível de autonomia militar frente à falta de conhecimento civil, de um lado, e a incipiente discussão pública sobre defesa (Diamint, 2002), somada à convicção na efetividade militar em tratar dos assuntos relacionados à guerra, de outro, (Lunn, 2002), fazem que os militares acabem por definir os objetivos da segurança e defesa nacionais (Kohn, 1997).

\section{Questões de gênero não são prioritárias}

A segunda etapa do mecanismo causal sugere que os militares não incluem o gênero entre os temas prioritários da defesa. Para checar essa afirmação, as evidências advém da segunda etapa do planejamento estratégico da defesa; isto é, após a prospecção do cenário, há a formulação da política.

${ }^{7}$ A ESG, ao longo de sua história, consolidou a imagem de uma instituição com atuação direta na política nacional, principalmente durante o regime militar (1964-1985), ao exercer influência na formação dos dirigentes políticos, civis e militares e da doutrina. Com o passar dos anos, contudo, houve o esvaziamento do órgão como entidade política, e o enfoque se voltou à sua missão principal, ofertando cursos de extensão e atualização (Barros e Chaves, s.d.). 
A principal atribuição dessa fase é a definição dos objetivos nacionais e das ações estratégicas para consecução de tais objetivos.

Nesse sentido, as Audiências Públicas realizadas com ministros da Defesa e comandantes das Forças Armadas na Comissão de Relações Exteriores e Defesa Nacional da Câmara dos Deputados (CREDN) e do Senado Federal (CRE), que tiveram como temática central a apresentação das principais questões da defesa, será a primeira evidência analisada a fim de depreender os objetivos do setor.

Isto posto, entre os anos de 2016 e 2019, foram realizadas quatro Audiências Públicas na CREDN com diferentes ministros da Defesa, com o propósito de discutir e informar os parlamentares sobre as prioridades da defesa.

Em abril de 2019, a apresentação foi realizada pelo Ministro da Defesa, General Fernando de Azevedo e Silva, que tratou de temas como: a formação da nacionalidade brasileira; a importância das Forças Armadas, suas atividades e atuações - Garantia da Lei e da Ordem (GLO) e segurança de grandes eventos -; as operações interagências e humanitárias; a política externa e o desenvolvimento nacional.

Um ano antes, em julho de 2018, foi realizada Audiência Pública semelhante, com o ministro General Joaquim Silva e Luna. Entre os temas de sua exposição, o ministro aludiu aos desafios de defesa e segurança nacional, a missão das Forças Armadas, o efetivo militar, o orçamento para consecução de ações estratégicas e prioritárias, a profissão militar, os valores militares, as peculiaridades da carreira, o sistema de proteção social dos militares, a defasagem remuneratória, os projetos estratégicos, as missões de paz, as operações de GLO e as atividades subsidiárias.

Em 2017, foi realizada Audiência Pública com o ministro da Defesa, Raul Jungmann, para apresentação das prioridades e diretrizes da política de defesa nacional. O ministro iniciou expondo a missão e o organograma de seu ministério. Expôs a continuidade, o histórico dos documentos de defesa e sua evolução. Destacou o entorno estratégico e a participação em missões de paz e humanitárias, elencou as principais ameaças ao Brasil e detalhou a questão orçamentária. Tratou, também, dos projetos das Forças, da Base Industrial de Defesa e das diversas atribuições subsidiárias realizadas em apoio à sociedade.

Em novembro do ano anterior, Raul Jungmann já havia estado presente na CREDN enquanto Ministro da Defesa. O ministro organizou uma apresentação em que foram expostas a missão, o efetivo e os papéis das Forças e do MD. Narrou a evolução histórica dos documentos de defesa e os principais conceitos utilizados. Apresentou o orçamento e as perdas sofridas nos anos anteriores, os eixos de atuação e os principais projetos de cada Força. 
Ainda nessa casa, no ano de 2017 foram realizadas três audiências com os comandantes de cada uma das Forças, para debater os Projetos Estratégicos, os programas de cooperação internacional na área da Defesa e os planos para o desenvolvimento do setor.

Em maio, a CREDN recebeu o comandante da Força Aérea Brasileira. Em sua apresentação, o comandante realizou um relato histórico, no qual narrou a origem e a evolução do poder aéreo, do Ministério da Aeronáutica e da Aeronáutica Brasileira. Mencionou, ainda, cada uma das concepções operacionais - controlar, defender e integrar. Encerrou apresentando os projetos estratégicos e frisou a diferença entre os investimentos realizados no setor pelo Brasil e em outros países.

Dias depois, também em maio, os programas da Marinha foram apresentados. Nesse momento, dispôs-se sobre o contexto marítimo brasileiro, as tarefas estratégicas e as principais ameaças da Marinha e do Brasil. Foram feitas, também, considerações sobre o pessoal e a necessidade de redução do efetivo até 2030. Dentre as prioridades, foram listadas: o Programa de Desenvolvimento de Submarinos, o Programa Nuclear da Marinha, a Corveta Classe "Tamandaré" e a obtenção da capacidade operacional plena. A apresentação se encerrou com o relato a situação orçamentária.

No mês de julho, o Exército realizou sua apresentação. Foram abordadas as atividades de GLO, os Projetos Estratégicos em execução (SISFRON, Guarani, Astros, Defesa Cibernética, Defesa Antiaérea e PROTEGER), o orçamento (contrastando os recursos necessários com aqueles disponibilizados), as práticas de cooperação internacional e as projeções futuras.

Frisa-se, no entanto, que dentre todos os pontos levantados pelos três comandantes, não houve nenhuma menção a projetos que visassem a igualdade de gênero e/ou melhorias nas condições de trabalho femininas para uma plena incorporação.

No Senado Federal foram realizadas três Audiências Públicas com ministros da Defesa na CRE, duas delas em 2016 e uma em 2017, todas com a finalidade de discutir as ações, programas, projetos e desafios do MD. Em 2017, o então ministro Raul Jungmann expôs questões relacionadas à Base de Alcântara, às atribuições subsidiárias das Forças e às operações de GLO.

Em novembro de 2016, o ministro Jungmann realizou uma exposição semelhante à apresentada na CREDN, excetuando a discussão com maior profundidade do Sistema de Proteção Social dos Militares das Forças Armadas. Meses antes, o então ministro da Defesa Aldo Rebelo foi convidado para debater a PND. Na ocasião, falou sobre os documentos norteadores e sobre a revisão do Congresso; destacou, ainda, a importância das Forças Armadas para a soberania.

Igualmente, foram à CRE no Senado, no ano de 2017, os comandantes das três Forças, a partir de requerimentos que solicitavam a presença para o debate dos projetos estratégicos e de questões ligadas à soberania nacional. O conteúdo foi o mesmo daquele transmitido na CREDN. 
Do conjunto de Audiências Públicas depreende-se que em nenhum momento, entre 2016 e 2019, foi tratado o tema das mulheres militares dentre as principais questões da defesa.

A investigação segue na tentativa de encontrar outras evidências que aumentem o grau de confiança no segundo elo do mecanismo, e recorre à observação das atas das reuniões celebradas no âmbito da Comissão de Gênero do Ministério da Defesa (CGMD) para verificar se os temas tratados são levados em consideração na formulação da política de defesa. ${ }^{8}$

A ata da 3a Reunião Ordinária (abril/2015), mostra uma discussão voltada à inserção da temática de gênero no Planejamento Político/Estratégico (2016-2019). Relata-se no documento que o Gerente da Divisão de Planejamento do Departamento de Planejamento Orçamentário e Financeiro, após discorrer sobre o processo de construção do PPA, afirmou que a promoção dos direitos humanos integraria uma das diretrizes estratégicas (Diretriz 15). Discorreu ainda sobre a dificuldade de se criar uma ação específica para tratar o tema "gênero" no orçamento da defesa, mas disse ser possível inseri-lo na contextualização de um dos objetivos (CGMD, 2015a).

Nos debates seguintes, o representante da Chefia de Assuntos Estratégicos (CAE) avaliou como preocupante estabelecer no PPA a ampliação da participação feminina em missões de paz, diante da possibilidade de não haver voluntárias. Outro participante achou temerário criar metas relacionadas à participação das mulheres. Para a Assessoria de Planejamento do MD, o tema poderia ser inserido na Estratégia Setorial de Defesa - ESD, na sessão Área de Pessoal, carecendo, para isso, de uma adequação das ações propostas ao orçamento, já bastante limitado (CGMD, 2015a).

Não obstante, o fato mais saliente desta ata é o informe da Assessoria Especial de Planejamento (ASPLAN) de que o processo de debates e consultas junto aos comandantes militares para formulação da Política Setorial de Defesa - PSD, e da ESD havia sido concluído antes de se ter conhecimento dos trabalhos desenvolvidos pela CGMD. Com isso, seria possível apenas uma inclusão tardia da temática nos documentos (CGMD, 2015a).

Na mesma reunião, os participantes manifestaram insatisfação com a utilização do termo "equidade" (por implicar em uma disposição paritária de homens e mulheres) e advertiram sobre possíveis questionamentos com o emprego da palavra "gênero". Ao final, em consenso, a Comissão propôs a seguinte Ação Setorial de Defesa: “Contribuir, no âmbito da Defesa, para a promoção da igualdade entre homens e mulheres em direitos e obrigações, nos termos da Constituição Federal" (CGMD, 2015a). Tal ação foi incluída na ESD de 2015, em último de uma lista de 132 ações, e sem estabelecer paralelo com nenhuma das demais.

${ }^{8}$ A CGMD foi criada em 2014, com caráter consultivo, sendo composta por representantes dos comandos das Forças Armadas e de diversos setores do Ministério da Defesa. 
Na 6ª Reunião Ordinária, em junho de 2016, a existência da CGMD foi questionada, ao passo que a Aeronáutica já cuidaria da inserção e do acompanhamento da mulher na instituição, independentemente do trabalho da Comissão. Em resposta ao ponto de vista, foi lembrado que o assunto "mulheres nas Forças Armadas", embora tratado por cada Força separadamente, é da competência central do MD. A esse comentário seguiram-se outros, ressaltando a importância das funções desempenhadas pela Comissão especialmente, para a produção de estudos e análises que garantam uma melhor apreensão do quadro e no assessoramento direto ao Ministério (CGMD, 2016a).

Não obstante a tentativa de requalificar a importância da Comissão, na prática observa-se um esvaziamento das discussões e uma irrisória capacidade de ação. Existem registros formais apenas de mais duas reuniões realizadas pela Comissão, uma delas em agosto de 2016 e outra em junho de 2017.

Na reunião celebrada em agosto, pontuou-se a baixa expressividade do Brasil na Conferência Internacional sobre Mulheres nas Forças Armadas, realizada em Trindade e Tobago (2016). Foi enviado apenas um representante, que era do sexo masculino, destoando dos demais países do continente americano, que demonstraram maior atenção ao tema, considerado estratégico. O Brasil, comparativamente aos outros Estados, mostrou-se bastante atrasado na implementação das ações, além de limitado a debates ultrapassados, como a possibilidade ou não de participação feminina em determinados postos. Nos demais países as discussões atingem patamares mais elevados, a exemplo do pleno aproveitamento das capacidades femininas (CGMD, 2016b).

As reuniões foram, então, pouco propositivas; não houve concretização de projetos de pesquisa planejados, e a Comissão participou apenas marginalmente nas tratativas para construção do Plano Nacional de Ação referente à Resolução $1325 .{ }^{9}$ A temática de gênero e o órgão criado para tratá-la possuem pequena expressão dentre os assuntos prioritários da defesa. As discussões são tardias, marcadas por estereótipos e limitadas ao âmbito da CGMD, logo, não são consideradas para a formulação da política de defesa.

A literatura indica que a indefinição de uma política de gênero, em especial no domínio militar, tem como primeira ação o silenciar das vozes femininas (Enloe, 2004). Ou seja, nesse meio, a delimitação dos objetivos e interesses particulares estão carregados por mais estereótipos de gênero (Goldstein, 2001), logo, não adentram os temas prioritários da agenda.

Há, portanto, um controle da agenda. As questões são confinadas a um escopo seguro. Previne-se a expansão de determinados tópicos por meio da manipulação dos valores da

\footnotetext{
${ }^{9}$ Os Planos Nacionais de Ação são responsáveis por reunir objetivos estratégicos e atribuir ações e medidas para diferentes ministérios e entidades governamentais, com o propósito de fomentar a igualdade de gênero e aumentar a participação feminina nos processos de construção e promoção da paz.
} 
comunidade, da criação de mitos, da desqualificação de grupos, do questionamento da legitimidade das questões - explorando incertezas e possíveis impactos negativos - e do ignorar da existência de problemas (Bachrach e Baratz, 1962; Cobb e Ross, 1976).

\section{Parlamentares se eximem da discussão}

A terceira etapa do mecanismo causal alvitra que os e as parlamentares se eximem da discussão do conteúdo dos documentos da defesa. Essa proposição foi a última a ser considerada, pois faz referência ao derradeiro estágio da segunda fase do planejamento estratégico da defesa, que se encerra com o encaminhamento à Presidência da República de mensagem com os documentos da defesa; sendo aquela responsável por analisá-los e remetê-los ao Congresso Nacional (Brasil, 2015).

As evidências para essa afirmação foram coletadas ao longo da tramitação dos textos das propostas de alterações na PND e END no Congresso, encaminhados para apreciação em 18 de novembro de 2016, por meio da Mensagem no 616 de 2016.

Após ser lido no Plenário do Congresso Nacional, em 13/03/2017, o Projeto de Decreto Legislativo no 847 foi encaminhado à Comissão Mista de Controle das Atividade de Inteligência CCAI, em 20/03/2017, e o Senador Fernando Collor (Pros) foi designado seu relator. O relatório descreveu, em linhas gerais, o conteúdo dos documentos, reiterou a sua importância e fez uma única recomendação no tocante às operações de GLO. O parecer da CCAI concluiu de forma favorável ao projeto.

No Senado Federal, a matéria foi submetida a dois turnos. A primeira sessão de discussão, por cinco oportunidades, não logrou deliberação e foi adiada. Na sexta oportunidade, em 05/12/2018, os registros do Diário do Senado Federal mostram que não houve nenhuma manifestação dos senadores, aprovando a matéria.

A matéria adentrou novamente a Ordem do Dia da sessão deliberativa ordinária no dia $12 / 12 / 2018$ e foi transferida para o dia seguinte, data em que foi aprovada mais uma vez sem discussão da matéria.

Na Câmara dos Deputados a matéria adentrou a pauta de duas Sessões Deliberativas Extraordinárias nos meses de junho e agosto/2018, porém deixou de ser discutida por encerramento da sessão. Em 04/09/2018 se deu o primeiro turno da votação, mas dada a ausência de oradores inscritos, a sessão foi encerrada sem discussão. Já na segunda sessão do primeiro turno, em 31/10/2018, houve maior participação, e alguns dos congressistas se inscreveram e teceram comentários a respeito dos documentos.

O Deputado Edmilson Rodrigues (PSOL-PA) posicionou-se de forma contrária à aprovação do projeto, uma vez que o processo de elaboração ocorreu com baixa participação da sociedade civil 
e poucos debates no Congresso. Dentre os posicionamentos favoráveis, grande parte destacou o atraso no andamento do Projeto, sendo de extrema urgência a aprovação.

O resultado da votação foi pela aprovação da matéria, em primeiro turno, seguindo para a discussão em segundo turno, o qual obedeceu ao interstício constitucional. Assim, em 08/11/2018, a matéria retornou à pauta, após não conseguir ser debatida no dia anterior. Nessa oportunidade, a Deputada Erika Kokay (PT-DP), que falaria em favor da matéria, fez um discurso motivado pelo resultado do processo eleitoral, ainda recente naquela circunstância, porém não adentrou a temática da Defesa.

Para falar contrariamente à matéria, o Deputado Glauber Braga (PSOL-RJ) não compareceu à sessão. Com isso, a discussão em segundo turno foi encerrada sem nenhum destaque, e o Projeto de Decreto Legislativo no 847 de 2017 foi aprovado. Em 14/12/2018, o Projeto foi transformado no Decreto Legislativo no 179 de 2018 e publicado no Diário Oficial da União. Como dito, a única recomendação após os 21 meses à disposição do Congresso foi relativa ao melhor detalhamento das operações de GLO.

Conquanto cumpra ao Legislativo a função de contribuir para o desenvolvimento e implementação da política, garantindo o controle político da defesa (Lunn, 2002), os parlamentares, que são pouco capacitados e informados (Donadio, 2000; Montoya, 2006), são também pouco proativos e eximem-se das discussões (Martins Filho et al., 2016).

As evidências ao longo da tramitação do projeto no Congresso tornaram flagrante o desinteresse, evidenciado pela lentidão com que a matéria foi tratada e culminando em uma aprovação fora do prazo. A falta de vontade política foi expressa por pareceres e debates superficiais.

\section{Considerações Finais}

Diante das evidências encontradas durante a investigação nos documentos e eventos analisados, foi possível ao final do processo aumentar o grau de confiança no mecanismo causal proposto. No caso brasileiro, a influência militar nos processos políticos teria contribuído para a ausência de gênero na política de defesa.

O modelo militar tradicional, conservador e excludente, ao mesmo tempo que fomenta a manutenção do status quo, limita o escopo da agenda a temas seguros, dificultando que o processo de integração feminina avance com maior rapidez (Schwether e Pagliari, 2016). Somam-se a isso o flagrante desinteresse político e social aos temas relacionados à defesa e a garantia constitucional de participação das Forças Armadas na política.

Desse modo, conclui-se que o mecanismo, ao operar no contexto brasileiro, deixou rastros que puderam ser coletados e agrupados de forma a aumentar a confiança que se tinha inicialmente. 
Embora soubéssemos que a influência militar na política permanecia alta no Brasil, mesmo após a redemocratização, não se sabia como isso poderia afetar as políticas de gênero para a defesa - daí o incremento à confiança inicial.

Por tratarmos de um fenômeno contemporâneo, tivemos facilidade no acesso aos dados. Contudo, independente daquilo que foi encontrado, a confiança no resultado é sempre parcial. Por essa razão, não existe a pretensão de convencimento de leitores e leitoras de que essa é a principal, e muito menos a única, causa atuando no fenômeno. O que se pretende é agregar mais uma possível causa, que ainda não havia sido considerada pela literatura. Todavia, o estudo em profundidade de outros casos se faz necessário para uma aspiração generalizante.

\section{Referências}

Acker, Joan. (1990) ‘Hierarchies, Jobs, Bodies: a theory of gendered organization’, Gender and Society, 14(2), p139-158.

ADESG, Associação dos Diplomados da Escola Superior de Guerra. (2019) ‘ESG sedia reunião para elaborar os Cenários de Defesa - 2040’. Disponível em: http://adesg-an.blogspot.com/2019/06/esgsedia-reuniao-para-elaborar-os.html. Acesso em: 28/12/2021.

Alison, Miranda. (2007) 'Wartime sexual violence: women's human rights and questions of masculinity', Review of International Studies, 33, p75-90.

Ascom, Assessoria de Comunicação Social. (2015) ‘Política Nacional de Defesa pautará debates da II Jornada de Estudos Estratégicos', Ministério da Defesa Governo Federal [online]. Disponível em: https://www.gov.br/defesa/pt-br/centrais-de-conteudo/noticias/ultimas-noticias/politicanacional-de-defesa-pautara-debates-da-ii-jornada-de-estudos-estrategicos. Acesso em: 28/12/ 2021.

Baaz, Maria e Stern, Maria. (2009) ‘Why do soldiers rape? Masculinity, violence and sexuality in the Armed Forces in the Congo', International Studies Quarterly, 53, p495-518.

Bachrach, Peter e Baratz, Morton. (1962) 'Two Faces of Power', American Political Science Review, 56(4), p947-95.

Barros, Alexandre e Chaves, Luís Guilherme B. 'Escola Superior de Guerra (ESG)', FGV-CPDOC. Disponível em: http://www.fgv.br/cpdoc/acervo/dicionarios/verbete-tematico/escola-superiorde-guerra-esg (Acesso: dez. 2019)

Beach, Derek e Pedersen, Rasmus. (2013) Process Tracing Methods, Foundations and Guidelines, Ann Arbor: University of Michigan Press.

Beach, Derek e Pedersen, Rasmus. (2019) Process Tracing Methods. 2ed, Ann Arbor: University of Michigan Press. 
Bennet, Andrew e Elman, Colin. (2007) 'Case Study Methods in the International Relations Subfield', Comparative Political Studies, 40(7).

Brasil. (2015) 'Sistema de Planejamento Estratégico de Defesa (SISPED)’ Ministério da Defesa [online]. Disponível em: https://bdex.eb.mil.br/jspui/handle/123456789/150 Acesso em: 28/12/2021.

Caprioli, Mary. (2000) 'Gendered Conflict', Journal of Peace Research, 37(1), p53-68.

Carreiras, Helena. (1999) 'Mulheres Militares em Portugal (1992-1998) Políticas, Processos e Protagonistas', Nação e Defesa, 88, p81-111.

Carreiras, Helena. (2004) 'Mulheres em contextos atípicos: lógicas de exclusão e estratégias de integração feminina nas forças armadas'. Etnográfica, 8(1), p91-115.

Carreiras, Helena. (2010) 'Gendered culture in peacekeeping operations', International Peacekeeping, 17(4).

Carvalho, José Murilo. (2019) Forças Armadas e política no Brasil. 3ed, São Paulo: Ed. Todavia.

CDI Center for Development Impact. (2015) 'Applying Process Tracing in Five Steps', Practice Paper Annex, 10.

CGMD, Comissão de Gênero do Ministério da Defesa. (2015a) 'Memória de Reunião n4/2015/CGMD', Ministério da Defesa.

CGMD, Comissão de Gênero do Ministério da Defesa. (2015b) ‘Memória de Reunião n5/2015/CGMD', Ministério da Defesa.

CGMD, Comissão de Gênero do Ministério da Defesa. (2016a) ‘Memória de Reunião n6/2016/CGMD', Ministério da Defesa.

CGMD, Comissão de Gênero do Ministério da Defesa. (2016b) ‘Memória de Reunião n7/2016/CGMD', Ministério da Defesa.

Choi, Seung-Whan e James, Patrick. (2004) 'Civil-Military Relations in a Neo-Kantian World, 18861992', Armed Forces E Society, 30(2), p227-254.

CRE, Comissão de Relações Exteriores e Defesa Nacional do Senado. (2016) ‘Audiência Pública com o Ministro de Estado da Defesa, Raul Jungmann', Senado Federal.

CRE, Comissão de Relações Exteriores e Defesa Nacional do Senado. (2017) ‘Audiência Pública com o Ministro de Estado da Defesa, Raul Jungmann', Senado Federal.

CRE, Comissão de Relações Exteriores e Defesa Nacional do Senado. (2017) ‘Audiência Pública Força Aérea Brasileira', Senado Federal.

CREDN, Comissão de Relações Exteriores e de Defesa Nacional. (2016) 'Reunião N 1417/16', Câmara dos Deputados.

CREDN, Comissão de Relações Exteriores e de Defesa Nacional. (2017a) 'Reunião N 0495/17', Câmara dos Deputados. 
CREDN, Comissão de Relações Exteriores e de Defesa Nacional. (2017b) 'Reunião N 0547/17', Câmara dos Deputados.

CREDN, Comissão de Relações Exteriores e de Defesa Nacional. (2018) ‘53247ª̊ Reunião, Audiência Pública', Câmara dos Deputados.

Diamint, Rut. (2002) Democracia y Seguridad en America Latina. Buenos Aires: Nuevo Hacer.

Donadio, Marcela. (2000) 'El Papel del parlamento en la defensa nacional', Fuerzas Armadas y Sociedad, 18(12), p139-154.

Duncanson, Claire; Woodward, Rachel. (2016) 'Regendering the Military: theorizing women's military participation', Security Dialogue, 47(1), p3-21.

Dunivin, Karen. (1997) 'Military Culture: a paradigm shift?', The Maxwell Papers, 10.

Enloe, Cynthia. (2004) The Curious Feminist: searching for women in a new age of empire. Berkeley: University of California Press.

Feaver, Peter. (2011) 'The Right to be Right', International Security, 35( 4), p87-125, 2011.

Finer, Samuel E. (1962) The Man on the Horse Back: the role of the military in politics. London: Pall Mall Press.

Giannini, Renata; Folly, Maíara e Lima, Mariana F. (2017) 'Situações extraordinárias: a entrada de mulheres na linha de frente das Forças Armadas brasileiras', Instituto Igarapé, 27.

Golby, James; Feaver, Peter e Dropp, Kyle. (2018) ‘Elite Military Cues and Public Opinion the use of Military Force', Armed Forces \& Society, 44(1), p44-71.

Héritier, Françoise. (1989) 'Masculino e Feminino' in Enciclopedia Einaundi, Lisboa: Imprensa Nacional.

Hinojosa, Ramon. (2010) 'Doing Hegemony: military, men, and constructing a hegemonic masculinity', The Journal of Men's Studies Press, 18(2), p179-194.

Hollan, Janet e Ramazanoglu, Caroline. (2002) Feminist Methodology: challenges and choices. London: SAGE Publications Ltd.

Huntes, Wendy. (1995) 'Politicians against Soldiers contesting the Military in Postauthorization Brazil', Comparative Politics.

Janowitz, Morris. (1967) O Soldado Profissional: um estudo social e político. Rio de Janeiro: Editora GRD.

Kohn, Richard. (1997) 'How Democracies Control the Military'. Journal of Democracy, 8(4), pp. 140-53.

Lunn, Simon. (2002) 'The Democratic Control of Armed Forces in Principle and Practice', The Quarterly Journal, 4, p83-102.

Melo, Carlos A. (1984) 'Processo político e participação', Revista de Informação Legislativa, 21(82), p135-148. 
Montoya, José. (2006) 'La conduccion democratica de la política pública de defensa: retos de um nuevo gobierno en democracia', Instituto de Defensa Legal.

NEE-CMS, Núcleo de Estudos Estratégicos Comando Militar do Sul. (2019) '1ํㅗ Reunião de Cenários de Defesa $2020 \quad-\quad 2040^{\prime} \quad$ [online]. Disponível em: http://www.nee.cms.eb.mil.br/index.php/component/content/article/60-noticias/177-1-reuniaopara-a-elaboracao-de-cenarios-de-defesa-2020-2040. Acesso em: 29/12/2021.

Oliveira, Eliézer Rizzo. (1987) ‘A doutrina de segurança nacional: pensamento político e projeto estratégico' in OLIVEIRA, E. R. (org.). Militares: pensamento e ação política. Campinas: Papirus.

PRS Group. (s.d.) International Country Risk Guide Methodology [Online]. Disponível em: https://www.prsgroup.com/wp-content/uploads/2012/11/icrgmethodology.pdf. Acesso em: 20/10/2019.

Schwether, Natalia e Pagliari, Graciela. (2016) 'As novas tendências militares: uma oportunidade para as mulheres?', Estudos Internacionais, 4(3), p45-58.

Schwether, Natalia. (2020) 'Sobre Gênero: uma análise qualitativa comparada das políticas de Defesa dos países sul-americanos', Revista Brasileira de Estudos Estratégicos, 12(23), p.79-100.

Segal, Mady. (2006) 'Gender and the Military' in Handbook of the Sociology of Gender, Boston: Springer.

Silva, Jennifer. (2008) 'A new generation of women? How female ROTC Cadets negotiate the tension between masculine military culture and traditional femininity', Social Forces, 87(2), p937-960.

Spencer, Anne e Podmore, David. (1987) In a Men's World: essays on women in male-dominated professions, Londres: Tavistock.

Stachowitsch, Saskia. (2012) 'Military gender integration and foreing policy in the United States: a feminist international relations perspective', Security Dialogue, 43(4), p305-321.

Stepan, Alfred. (1988) 'As Prerrogativas Militares nos Regimes Pós-Autoritários: Brasil, Argentina, Uruguai e Espanha' in Stepan, Alfred (org.) Democratizando o Brasil. São Paulo: Ed. Paz e Terra, pp.521-562.

Stern, Maria. (2011) 'Whores, Men, and Other Misfits: undoing 'feminization' in the armed forces in the DRC', African Affairs, p.1-23.

Tickner, Ann. (1999) 'Why women can't rule the world', International Studies Review, 1(3).

True, Jacque. (2010) 'Normalising gender in global governance' Gender in International Governance Conference, Geneva: Graduate Institute for International and Development Studies.

Winton, Harold. (2000) 'Introduction: on military change' in Winton, Harold e Mets, David. (eds) The Challenge of Change: military institutions and new realities, 1918-1941. London: University of Nebraska Press.

Yoder, Janice. (1991) 'Rethinking Tokenism: Looking beyond Numbers', Gender and Society, 5(2), p178-192. 
Young, Thomas. (2006) 'Military Professionalism in Democracy' in Bruneau, Thomas, Tollefson, Scott (eds.). Who Guards the Guardians and How: democratic civil-military relations, Austin: University of Texas Press.

Zaverucha, Jorge. (1998) Sarney, Collor, Itamar, FHC e as Prerrogativas Militares (1985-1998). Chicago: Meeting of Latin American Studies Association.

Zaverucha, Jorge. (2005) A Constituição Brasileira de 1988 e a Permanência de seu Legado Autoritário in Zaverucha, Jorge (ed) FHC, Forças Armadas e Polícia: Entre o Autoritarismo e a Democracia. Rio de Janeiro: Ed. Record, p.51-89. 